\title{
Thermal stability and flammability of butadiene-styrene rubber nanocomposites
}

\author{
Przemysław Rybiński • Grażyna Janowska • \\ Małgorzata Jóźwiak • Agnieszka Pająk
}

Bretsznajder Special Chapter

(C) The Author(s) 2012. This article is published with open access at Springerlink.com

\begin{abstract}
This paper presents the effect of halloysite intercalated with a base or modified montmorillonite on the thermal properties and flammability of peroxide and sulfur vulcanizates of styrene-butadiene rubber (SBR). Based on the test results obtained by means of thermal analyses (DTA, TG, DTG, and DSC), oxygen index and microcalorimeter (FAA) it has been found that the thermal stability and flammability of the nanocomposites investigated depend on the spatial network structure as well as the content and type of nanoadditive in the vulcanizate obtained. The nanofillers used considerably reduce the flammability and fire hazard of the cross-linked SBR.
\end{abstract}

Keywords Intercalated halloysite $\cdot$ Montmorillonite Thermal stability $\cdot$ Flammability

\section{Introduction}

Elastomers that do not contain a filler compound are practically insignificant in any applications; therefore, in practice, an elastomers is commonly combined with fillers to form a mixture, whose filler content is usually $\sim 30-50 \%$.

The fillers generate stronger elastomers and are of great influence on the thermal stability and flammability composites. Organic and inorganic fillers, such as carbon black

P. Rybiński ( $)$ · M. Jóźwiak

Department of Management and Protection Environment,

Jan Kochanowski University of Kielce, Kielce, Poland

e-mail: przemyslaw.rybinski@ujk.edu.pl

G. Janowska · A. Pająk

Institute of Polymer and Dye Technology, Technical University

of Łódź, Łódź, Poland or silica, are often added to the elastomers. Usually these fillers are mechanically introduced into a polymer via milling. This milling is a slow, energy-intensive process that may cause chemical and thermal degradation of the polymer chains. Moreover, undesirable particulate agglomerates often remain even after aggressive milling. Small, separated particles are ideal for reinforcing a polymer matrix and improvement their thermal and barrier properties $[1,2]$.

With the rapid development of nanotechnologies and nanomaterials since 1990s, the studies on polymer-based nanocomposites have been extensively carried out in order to find their promising alternatives to traditional composites, though mainly focused on general mechanical, thermal properties, and filler dispersion. Properties of polymers which have shown substantial improvements due to the incorporation of nanoparticles (amount from 3 to $15 \%$ ), include:

- mechanical properties, e.g., strength, modulus, and dimensional stability

- decreased permeability to gases, water, and hydrocarbons

- thermal stability

- flame retardancy and reduced smoke emissions

- chemical resistance

- electrical and thermal conductivity

- optical clarity in comparison to conventionally filled polymers

Uniform dispersion of nanoparticles produces ultra-large interfacial area per volume between the nanoelements and host polymer. This immense internal interfacial area and the nanoscopic dimensions of nanoelements, fundamentally distinguish polymer/nanocomposites from traditional composites of elastomers [3]. 


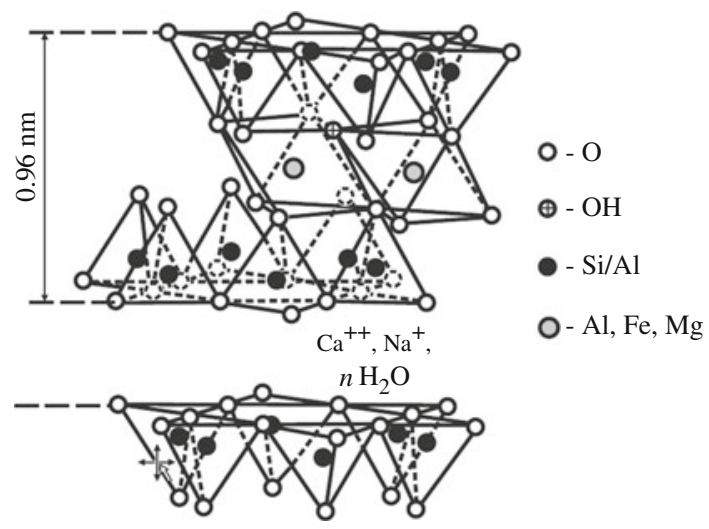

Fig. 1 Structure of montmorillonite [7]

Among various nanoparticles, clay minerals, carbon, and halloysite nanotubes or silica are more often used in enhancing physical, mechanical, and thermal properties of polymers $[4,5]$.

The layer silicate, e.g., mica, fluoromica, hectorite, fluorohectorite, and montmorillonite (MMT) belongs to the structural family known as the 2:1 phyllosilicates. Their crystal structure consists of layer made up of two silica tetrahedral sheets fused to edge-shared octahedral sheets of either aluminum or magnesium hydroxide (Fig. 1). Stacking of the layers leads to a regular Van der Waals gap between the layers. Isomorphic substitution within the layers generates charge deficiency of the clay. One important consequence of charge nature of the clays is that they are generally highly hydrophilic species and therefore naturally incompatible with a wide range of polymer types. For this reason clay must be modified with a surfactant in order to make the gallery space sufficiently hydrophobic to permit it to interact with the polymer. The most commonly used surfactants are primary, secondary, tertiary, and quaternary alkylammonium or alkylphosphonium cations [6, 7].

When the layered silicates are associated with the polymer, depending on the nature of the components used, nanocomposites can be obtained.

In the literature, the polymer-clay nanocomposites are generally classified into three groups according to their structure, i.e., nanocomposites with intercalated, exfoliated, or both of intercalated and exfoliated structures. Among them, the completely exfoliated nanocomposites are desired due to the fact that exfoliated layers exhibit the greatest reinforcement and barrier properties [7].

There are many reviews and books discuss the flame retarded properties of polymer/clay nanocomposites (PCL). The current researches of PCL mainly focus on the effect of manufacturing method, microstructure, and organic treatment of clay and residue investigation on flame retarded properties [4-11].

In the case of polymer/nanocomposites one of the most used fillers are carbon nanotubes (CNTs) and for some time now halloysite nanotubes (HNTs). Carbon nanotubes are categorized as single-walled nanotubes (SWCNTs), multiwalled nanotubes (MWCNTs), and double-walled nanotubes (DWCNTs), which are of minor importance [3, 12]. Most SWCNTs have a diameter of close to $1 \mathrm{~nm}$, with a tube length that can be many thousands of time longer. Carbon nanotubes exist as a macromolecule of carbon, analogous to sheet of graphite rolled into cylinder. The chemical bonding between carbon atoms inside nanotubes is always of $s p^{2}$ type, the same as in graphite, and provides them unique strength. Moreover, they align themselves into ropes held together by the Van der Waals force and can merge together under high pressure, trading some $s p^{2}$ bonds to $s p^{3}$ and producing very strong wires of nanometric lateral dimension [13].

The application of carbon nanotubes in flame retarded polymer material was first discovered by Kashiwagi in 2002 [14]. In general, the research results show that the single-walled carbon nanotube is more effective on the reduction of flammability properties than multi-walled carbon nanotube. Research found that the carbon nanotubes after crushing substantially delay the ignition time while maintaining much reduced heat released rate. For the synthesis of CNTs three main synthetic methods are used: arc-discharge, laser ablation, and catalytic methods such as chemical vapor deposition [3, 12]. Unfortunately all mentioned above methods are very expensive, what eliminate CNTs as an effective polymer flame retardant from industrial applications.

In recent time silicate nanotubes of the mineral halloysite have been investigated as an alternative type polymernanofiller to CNTs. Halloysite is naturally occurring aluminosilicate, which combine the chemistry of montmorillonite and the geometry of carbon nanotubes. The chemical formula of halloysite is $\mathrm{Al}_{2}\left[\mathrm{Si}_{2} \mathrm{O}_{5}(\mathrm{OH})_{4}\right] \times 2 \mathrm{H}_{2} \mathrm{O}[15,16]$. It mainly consist as a hollow tubes with dimensions of up to $10 \mu \mathrm{m}$ in length and an outer diameter in order of 30-100 nm. Halloysite is a 1:1 layered aluminosilicate consisting of double layers joined together through apical oxygen atoms. One side of double layer is gibbsite-like with aluminum atoms octahedrally coordinated with four oxygen atoms and two hydroxyl groups. The other side is a 2-D silicate layer structure, where silicon atoms are tetrahedrally coordinated with four oxygen atoms. The double layers are connected as sheets to other double layers via hydrogen bonds [17-19] (Fig. 2).

Halloysite particles are readily obtainable and are much cheaper than other nanoparticles such as CNTs. More importantly, the unique crystal structure of halloysite particles may have the potential to provide cheap alternatives to expensive CNTs because of their tubular structure in nano-scale.

The study presents results of the effect halloysite activated with sodium hydroxide on thermal properties and 


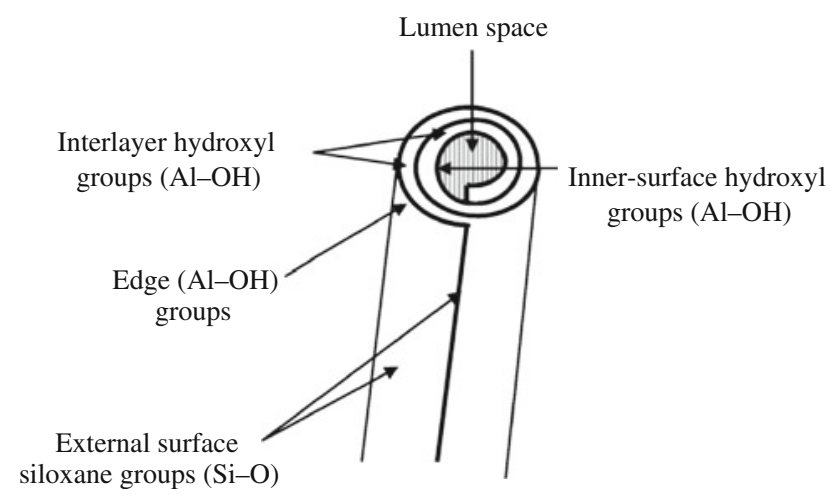

Fig. 2 Schematic structure of a halloysite nanotube [18]

combustibility of styrene-butadiene rubber. The results of these investigations have been compared with influence of montmorillonite modified by means of various organic compounds on the same properties of styrene-butadiene rubber.

\section{Experimental}

\section{Materials}

The object of our study was styrene-butadiene rubber (SBR), KER 1500 form Synthos, containing $23.5 \%$ of combined styrene. The rubber was cross-linked by means of dicumyl peroxide (DCP) in the presence of zinc oxide $(\mathrm{ZnO})$ or by means of sulfur in the presence of $\mathrm{ZnO}$ and $\mathrm{N}$-cyclohexyl-2-benzoylsulfenamide (Tioheksam CBS). The resultant peroxide vulcanizate was denoted with $\mathrm{SN}$, while the sulfur vulcanizate with SS. The following nanofillers were used as fillers of the elastomeric blends: Nanofil 2, Nanofil 5, and Nanofil 15 from Süd-Chemie (Table 1; Fig. 1) and halloysite derived from the Dunino deposit near Legnica (Poland), intercalated by means of sodium hydroxide (Fig. 2). The nanocomposites tested contained 5, 8, and $15 \mathrm{phr}$ (phrparts by wt. per hundred parts by wt. of rubber) of activated halloysite (SNH5, SNH8, SNH15, SSH5, SSH8, and SSH15) or $8 \mathrm{phr}$ of appropriate nanofiller (SNN2, SNN5, SNN15, SSN2, SSN5, and SSN15).

The alkaline activation of halloysite as the acidic intercalation reported by the authors [20] was aimed at the exposure of halloysite nanotubes (HNTs) through the removal of higher aliminosilicate acids (alofane acids) from their surface and space between them. The activation consisted in treating halloysite with $5 \mathrm{M} \mathrm{NaOH}$ solution for $8 \mathrm{~h}$ at a temperature of $60{ }^{\circ} \mathrm{C}$. Once the reaction mixture was cold halloysite was filtered off and rinsed with distilled water. In the next stage of intercalation, the filler was treated with an aqueous saturated solution of sodium acetate followed by stirring for $8 \mathrm{~h}$ at room temperature with the use of a mechanical stirrer. After that time the filler was filtered off, rinsed with distilled water until $\mathrm{pH}$ 6-7 and dried to a constant mass in a vacuum dryer at $30-35^{\circ} \mathrm{C}$.

The photographs of unactivated and activated halloysite were taken with the use of an electron microscope SEM Quanta 250 FEG (FEI Company) equipped with an electron gun and field emission (Schottky's emitter) (Figs. 3, 4).

\section{Methods}

Elastomeric blends were prepared at room temperature with the use of a laboratory roll stand with roller

Table 1 Characteristic of use aluminosilicates-producer data

\begin{tabular}{lllcl}
\hline Trade mark (symbol) & Producer & Modifying agent & Average size of grains/ $\mu$ m & Interlayer spacing/nm \\
\hline Nanofil 2 (N2) & Süd-Chemie & Ampholytic compound SBMAC & 8 & 1.8 \\
Nanofil 5 (N5) & Süd-Chemie & Ampholytic compound SMAC & 8 & 2.8 \\
Nanofil 15 (N15) & Süd-Chemie & & 25 & 2.8 \\
\hline
\end{tabular}

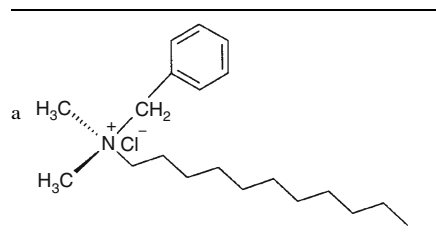

SBMAC stearilobenzylodimetyloammonium chloride

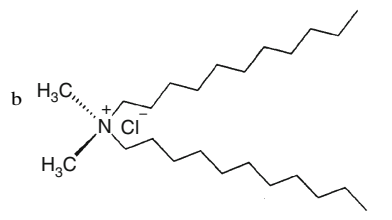

SMAC distearilodimetyloammonium chloride 
Fig. 3 Photographs of unactivated halloysite
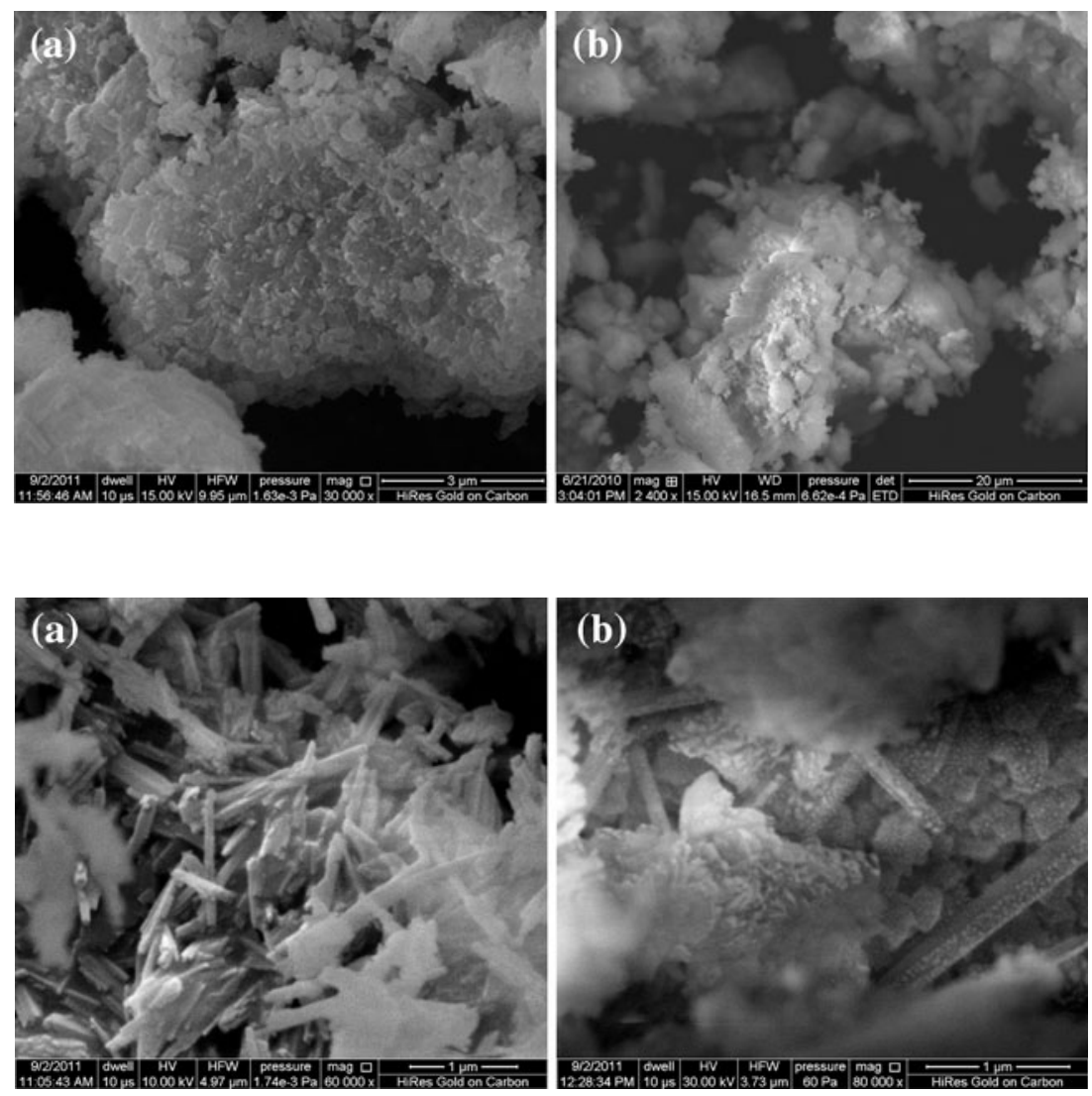

Fig. 4 Photographs of activated halloysite dimensions: $D=200 \mathrm{~mm}, L=450 \mathrm{~mm}$. The rotational speed of the front roller was $20 \mathrm{rpm}$, friction ratio 1.1.

The vulcanization of the blends was performed in steel molds placed between electrically heated press plates. The optimal vulcanization time $(\tau 0.9)$ at a temperature of $160{ }^{\circ} \mathrm{C}$ was determined by means of a WG- 2 vulcameter.

The thermal properties of aliminosilicates and the vulcanizates containing them were tested under air within the temperature range of $25-800{ }^{\circ} \mathrm{C}$, by means of a derivatograph from MOM (Budapest), using $\mathrm{Al}_{2} \mathrm{O}_{3}$ as reference compound. Weighed portions amounted to $90 \mathrm{mg}$, heating rate $7.9^{\circ} \mathrm{C} \times \min ^{-1}$, and the thermal curve sensitivities were as follows: $\mathrm{TG}=100$, DTA $=1 / 5$, DTG $1 / 30$. The thermal analysis under neutral gas within the temperature range of $-100-500{ }^{\circ} \mathrm{C}$ was carried out by the differential dynamic calorimetry using a DSC-204 microcalorimeter from Netzsch. Weigher portions were 5-7 $\mathrm{mg}$ and the heating rate $10{ }^{\circ} \mathrm{C} \times \mathrm{min}^{-1}$.

The measurements of wide-angle scattering of X-radiation (WAXS) in the modified montmorillonites and montmorillonite-containing nanocomposites were performed at room temperature by means of an X-ray apparatus from Phillips at the Center of Molecular and Macromolecular Studies, the Polish Academy of Science, in Lodz. Diffraction patterns were recorded within the angle range $2 \theta=1-7^{\circ} ;$ measurement step $0.05^{\circ}$; measurement time $25 \mathrm{~s}$; radiation $\mathrm{CuK} \alpha(\lambda=0.15418$ $\mathrm{nm}$ ); operation in transmission mode. The apparatus was calibrated at the beginning of each measurement series. The samples of the nanocomposites tested were disintegrated before analysis by means of a CAT X520D homogenizer (revolutions 16-30,000), cooled in a liquid nitrogen, transferred onto a polystyrene holder and placed in a disposable measurement ring. The WAXS measurement of the montmorillonites tested was a reference measurement for nanocomposites.

The flammability of nanocomposite was determined by the method of oxygen index (OI) using an apparatus from Fire Testing Technology Ltd and $50 \times 10 \times 4 \mathrm{~mm}$ samples. At a constant nitrogen flow rate in a measurement column $(D=75 \mathrm{~mm})$ amounting to $40 \pm 2 \mathrm{~mm} \times \mathrm{s}^{-1}$, the concentration of oxygen was selected so that the sample could be completely burned within $180 \mathrm{~s}$. The sample tip was ignited for $5 \mathrm{~s}$ by means of a gas burner supplied with propane-butane mixture. The value of OI was calculated from the following formula $[20,21]$ :

$\mathrm{OI}=\left(c_{\mathrm{F}}+k \times d\right) \div 100$

where $C_{F}$ is the final oxygen concentration, at which a sample is burned within $180 \mathrm{~s}, d$ the step size between oxygen concentration changes during the test procedure, and $k$ the coefficient of proportionality. 
We also tested flammability in air using identical samples as in the case of OI method. A sample in a vertical position was ignited with a gaseous burner as before for $5 \mathrm{~s}$ and its combustion time $\left(t_{\mathrm{s}}\right)$ was measured.

The vulcanizates under investigation were examined by means of an FAA micro-calorimeter from Fire Testing Technology Limited. The temperature of pyrolyser was $750{ }^{\circ} \mathrm{C}$, while that of combustor $900{ }^{\circ} \mathrm{C}$. During measurement the following parameters were recorded: ignition temperature, maximal heat emission rate, total heat emitted, heat capacity, and percentage oxygen consumption [20].

\section{Results and discussion}

The base- as acid-activated halloysite [20] show a threestage decomposition within the temperature range of $\Delta T=35-780^{\circ} \mathrm{C}$ (Fig. 5). The first thermal decomposition stage of halloysite occurring at $\Delta T_{1}=35-130{ }^{\circ} \mathrm{C}$, accompanied by the endothermic process, recorded in the DTA curve, is due to the desorption of water physically combined with the surface of aluminosilicate, whose content amounts to $5.6 \%$ by wt. At $\Delta T_{2}=130-440{ }^{\circ} \mathrm{C}$ the second thermal decomposition stage occurs, which is connected with the release of water physically occluded in nanotubes as well as the water chemically combined with the halloysite surface. This stage is accompanied by a $10 \%$ sample weight loss. The final stage of thermal decomposition occurring at

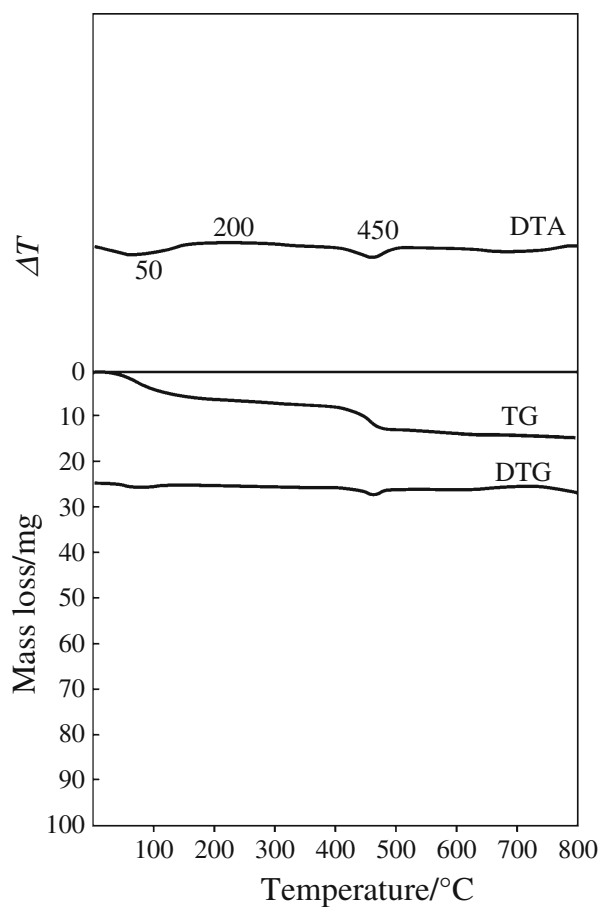

Fig. 5 Thermal curves of intercalated halloysite
$\Delta T_{3}=440-780{ }^{\circ} \mathrm{C}$ is connected with the combustion of the carbon fraction occurring in the form of carbonates and the overall organic carbon on the surface of HNTs. This stage is accompanied by a sample mass loss amounting to about $15.6 \%$.

From the derivatographic analysis of Nanofils (N2, N5, and N15) it follows that they undergo partial four-stage decomposition within the temperature range of $50-650{ }^{\circ} \mathrm{C}$ [22]. The first thermal decomposition stage of the nanoclays modified, occurring at $\Delta T_{1}=50-180^{\circ} \mathrm{C}$, accompanied by the broadened exothermic process recorded in the DTA curve, is due to the desorption of the physically combined water and low-molecular-weight substances present on the surface of nanoadditives (Table 2; Fig. 6). The nanofillers used by us were modified with organic ammonium salts with a low thermal stability. The thermal degradation of the modifier used proceeds by Hofman's elimination or nucleophilic substitution $\mathrm{S}_{\mathrm{N}} 2$. Depending on the structure of the carbon chain attached to the nitrogen atom in the ammonium salts used (Table 1), this process is recorded in the TG curves of nanocomposites at $\Delta T_{2}=180-300{ }^{\circ} \mathrm{C}$ [6]. The maximal thermal decomposition rate of the organically modified laminar silicates (OLS) occurs at a temperature of $240{ }^{\circ} \mathrm{C}$ (Fig. 6). In the initial stage of the thermal decomposition of the nanofillers tested, are formed and desorbed from the aluminosilicate surface small-particle olefin and amine compounds derived from the decomposition of the ammonium-organic modifier that simultaneously initiate the process of detaching the acidic hydrogen atom from the montmorillonite surface, to which the ammonium cation is attached. The presence of the acidic proton, $\mathrm{H}^{+}$, influences the degradation and cyclization of the nanocomposite at elevated temperatures $[6,22,23]$. With increasing temperature up to $300-500{ }^{\circ} \mathrm{C}$, $\left(\Delta T_{3}\right)$, organic compounds with a higher molecular weight are also desorbed from the surface of aluminosilicate. The final thermal decomposition stage of the nanofillers tested occurring at $\Delta T_{4}=500-650{ }^{\circ} \mathrm{C}$ is connected with the dehydration of the water chemically combined with the montmorillonite surface.

The results of derivatographic analysis listed in Table 3 show that the thermal stability of the cross-linked SBR

Table 2 The results of thermal analysis of nanofiles [25]

\begin{tabular}{llllll}
\hline Symbol & $Z_{\mathrm{H}_{2} \mathrm{O}} / \%$ & $T_{5} /{ }^{\circ} \mathrm{C}$ & $T_{\mathrm{R}} /{ }^{\circ} \mathrm{C}$ & $\mathrm{d} m / \mathrm{d} t / \mathrm{mm}$ & $P_{800} / \%$ \\
\hline $\mathrm{N} 2$ & 0.0 & 205 & 170 & 5.0 & 78.0 \\
$\mathrm{~N} 5$ & 2.2 & 230 & 210 & 3.0 & 63.3 \\
$\mathrm{~N} 15$ & 1.7 & 210 & 195 & 5.0 & 56.1 \\
\hline
\end{tabular}

$Z_{\mathrm{H}_{2} \mathrm{O}}$ physically bounded water, $T_{5}$ temperature of sample $5 \%$ mass loss, $T_{\mathrm{R}}$ initial temperature of nanoadditive thermal decomposition, $\mathrm{d} m \times \mathrm{d} t^{-1}$ maximum rate of thermal decomposition of nanoadditive, $P_{800}$ residue after heating of nanoadditive up to $T=800{ }^{\circ} \mathrm{C}$ 


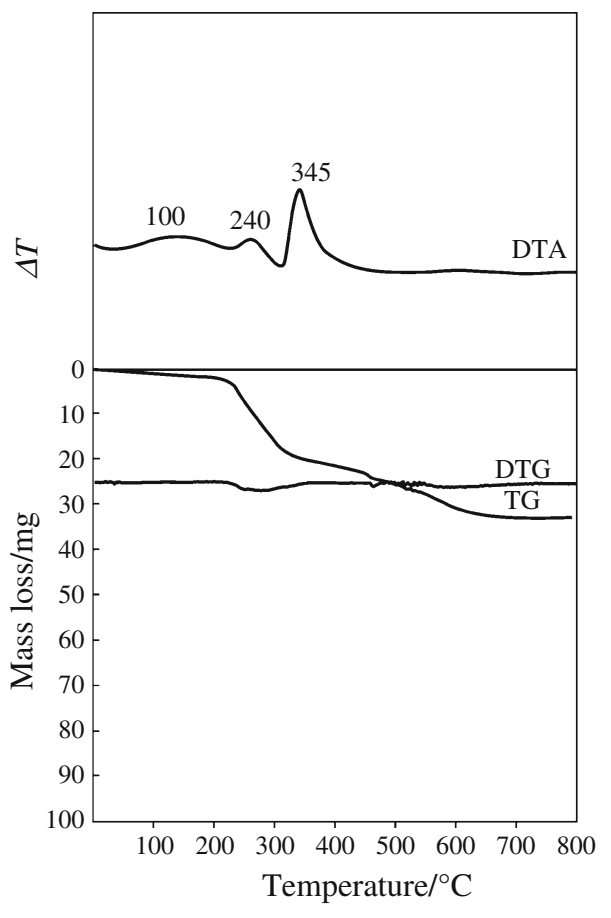

Fig. 6 Thermal curves of Nanofil 5

rubber depends on the method of its cross-linking and consequently on the structure of spatial network [20, 21, 24]. The nanoadditives used do not explicitly influence the thermal stability of the vulcanizates under investigation.
The halloysite intercalated with a base practically does not change it thermal stability determined by the $T_{5}$ and $T_{50}$ coefficients of both peroxide and sulfur nanocomposites. A similar influence on the thermal stability of peroxide vulcanizates is exerted by the addition of modified aluminosilicates. However, under the influence of these nanoadditives the thermal stability of sulfur vulcanizates (SN2, SSN5, and SSN15) is decreased as shown by the coefficient $T_{5}$. The lower thermal stability of sulfur nanocomposites containing appropriately modified aluminosilicates in relation to the unfilled vulcanizate (SS) probably results from Hofman's degradation, which is initiated with acidic protons formed not only as a result of the decomposition of quaternary ammonium salts but also the side products of cross-linking-containing sulfur.

The comparative analysis of the measurement results obtained by the method of derivatography leads to a conclusion that the presence of modified halloysite considerably increases the residue after the thermal decomposition of SBR vulcanizates $\left(P_{\mathrm{w}}\right)$, especially that of sulfur vulcanizates (Table 3 ). The coefficient $P_{\mathrm{w}}$ increases with increasing halloysite content in the polymeric material, which indicates that its presence facilitates the processes of cyclization and carbonization occurring during the thermal decomposition of cross-linked SBR. However, one should underline that the addition of modified halloysite as well as montmorillonite clearly decreases the thermal decomposition rate $(\mathrm{d} m / \mathrm{d} t)$ of cross-linked styrene-butadiene rubber.

Table 3 The results of thermal analysis vulcanizates of butadiene-styrene rubber

\begin{tabular}{|c|c|c|c|c|c|c|c|}
\hline Sample & $T_{5} /{ }^{\circ} \mathrm{C}$ & $T_{50}{ }^{\circ} \mathrm{C}$ & $\mathrm{d} m \times \mathrm{d} t^{-1} / \mathrm{mm}$ & $T_{\text {RMAX }} /{ }^{\circ} \mathrm{C}$ & $P w / \%$ & $T_{\mathrm{s}} /{ }^{\circ} \mathrm{C}$ & $P_{800} / \%$ \\
\hline SBR & 270 & 410 & 65 & 405 & & 505 & 5 \\
\hline SN & 350 & 419 & 80 & 415 & 19 & 475 & 5 \\
\hline SS & 300 & 400 & 70 & 365 & 20 & 490 & 8,8 \\
\hline SNH5 & 335 & 415 & 50 & 405 & 22.2 & 500 & 10,5 \\
\hline SNH8 & 355 & 415 & 50 & 400 & 25.5 & 490 & 11,6 \\
\hline SNH15 & 360 & 415 & 53 & 405 & 28.9 & 485 & 6.67 \\
\hline SSH5 & 305 & 405 & 50 & 395 & 27.2 & 505 & 11.1 \\
\hline SSH8 & 300 & 415 & 49 & 395 & 28.3 & 505 & 12.7 \\
\hline SSH15 & 315 & 415 & 51 & 400 & 32.7 & 510 & 17.2 \\
\hline SNN2 & 300 & 415 & 58 & 410 & 23 & 475 & 8.8 \\
\hline SNN5 & 350 & 415 & 56 & 410 & 23.5 & 475 & 10 \\
\hline SNN15 & 355 & 410 & 56 & 405 & 24.5 & 480 & 12.2 \\
\hline SSN2 & 260 & 400 & 45 & 400 & 24.5 & 480 & 10 \\
\hline SSN5 & 280 & 405 & 40 & 400 & 23 & 490 & 11.1 \\
\hline SSN15 & 300 & 410 & 45 & 400 & 23 & 480 & 12.2 \\
\hline
\end{tabular}

$S N$ peroxide vulcanizate, $S S$ sulfur vulcanizate, $S N H X$ peroxide vulcanizates contained 5, 8 and 15 phr of activated halloysite (SNH5, SNH8, SNH15), SSHX sulfur vulcanizates contained 5, 8 and $15 \mathrm{phr}$ of activated halloysite (SSH5, SSH8, SSH15), SNNX peroxide vulcanizates contained 8 phr of appropriate nanofiller (SNN2, SNN5, SNN15), SSNX sulfur vulcanizates contained 8 phr of appropriate nanofiller (SSN2, SSN5, SSN15), $T_{5}$ and $T_{50}$ temperature of sample 5 and $50 \%$ mass loss, respectively, $\mathrm{d} m \times \mathrm{d} t^{-1}$ maximum rate of thermal decomposition of vulcanizates, $T_{\mathrm{RMAX}}$ temperature of maximum rate of thermal decomposition of vulcanizates, $P_{\mathrm{w}}$ residue after the thermal decomposition of vulcanizates, $T_{\mathrm{s}}$ temperature of residue burning after the thermal decomposition of vulcanizates, $P_{800}$ residue after heating up to $T=800{ }^{\circ} \mathrm{C}$ 
The decrease in the decomposition rate of the vulcanizates under investigation under thermo-oxidative conditions exerts a positive influence on the reduction in their flammability. This results from the formation of lower quantities of volatile and flammable products of destruction passing to the gaseous zone of combustion, which reduces the rate of free-radical reactions proceeding in flame.

From literature reports it follows that the reduction in the flammability of polymeric materials-containing montmorillonite is due to the structure of a boundary layer formed during their combustion, whose isolating properties are the better, the higher the exfoliated structure content is in the given nanocomposite. Based on the previous studies of the authors and literature data, it has been found that the incorporation of the nanoclay modified in a quantity from 1 to $3 \mathrm{phr}$ into the rubber matrix causes that the content of the exfoliated structure in the polymeric matrix is dominating, but the quantity of the exfoliated/intercalated nanoclay is insufficient to form a thermally stable carbon layer. The best barrier effect is obtained with the nanoadditive content at a level of 5-8 phr $[9,25]$.

The assessment of the intercalation of montmorillonite layers by SBR chains was carried out on the basis of the WAXS analysis results. Figure 7 shows the X-ray curves used to estimate the distances between the nanofiller layers. In the case of Nanofils N5 and N15, these distances are similar as indicated by the peaks recorded at the angle $2 \theta=2.5^{\circ}$ in the curves, which corresponds to a distance between layers of about $3.5 \mathrm{~nm}$. Nanofil N2 shows a peak at $2 \theta=4.5^{\circ}$, which testifies to the occurrence of uniform distances amounting to about $2 \mathrm{~nm}$.

The analysis of curves presented in Fig. 8 indicates the intercalation of nanofillers by SBR since the single peak recorded at $2 \theta=2.0^{\circ}$ occurs in all the elastomeric material tested regardless of the type of montmorillonite modifier.

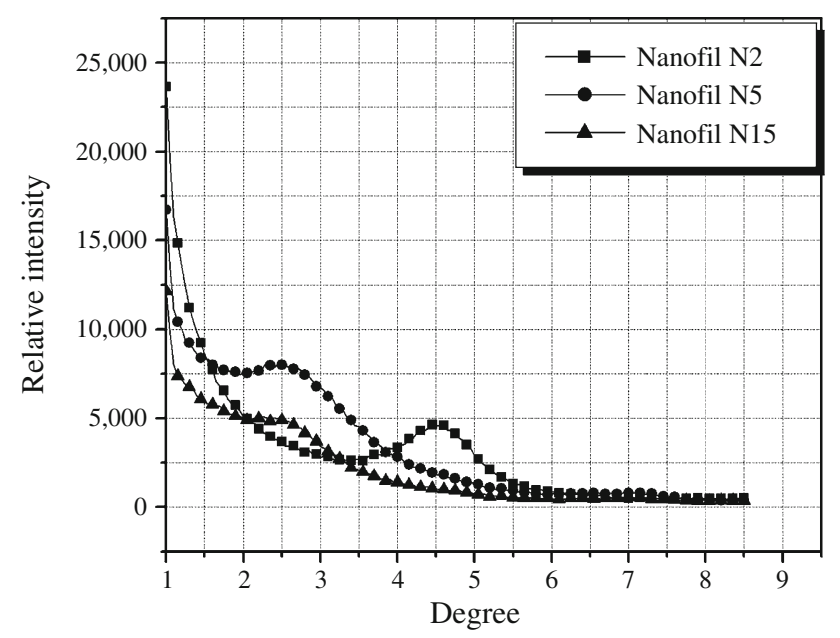

Fig. 7 The results of WAXS of Nanofiles

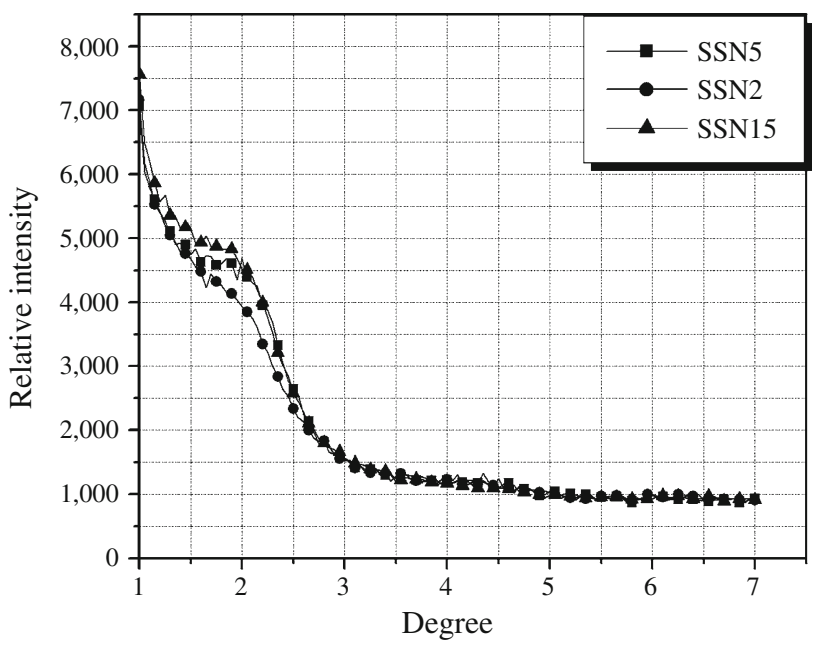

Fig. 8 The results of WAXS of nanocomposites

It corresponds to the distance between plates amounting to 4.4-4.6 nm. Thus, the increase in the distance between nanofiller layers indicates an intercalation character of the nanocomposites obtained [26].

From the DSC results it follows that during cooling SBR passes from the elastic to the glassy state at $T=-59{ }^{\circ} \mathrm{C}$ (Fig. 9). The transition from the glassy to the elastic state during heating occurs at $T=-52{ }^{\circ} \mathrm{C}$. The temperature range, within which the segmental mobility of SBR macromolecular chains decays (cooling process) is narrower than that, within which the segmental mobility restarts during heating. At $T=267{ }^{\circ} \mathrm{C}$ in the DSC curves one can observe a great exothermic process connected with the thermal cross-linking of SBR, whose maximal rate occurs at $T=370{ }^{\circ} \mathrm{C}$ (Table 4; Fig. 9). The great change in the enthalpy of this process, which consists in the free-radical polymerization of butadiene units, indicates that it proceeds with a considerable yield. The thermally cross-linked SBR undergoes destruction and the temperature of the maximal thermal decomposition rate is $458{ }^{\circ} \mathrm{C}$ (Table 4; Fig. 9). The cross-linking of SBR by means of sulfur or dicumyl peroxide does not change the character of its thermal processes under a neutral gas (Figs. 9, 10). Under the influence of the lateral sulfide bonds the glass transition temperature $\left(T_{\mathrm{g}}\right)$ of the elastomer is increased (Table 4; Figs. 9, 10). From the comparative analysis of the data given in Table 4 it follows that the increase in the glass transition temperature of SBR is also due to both halloysite and nanofillers in the case of the polymer cross-linked with peroxide (SNH5, SNH8, SNH15 and SNN2, SNN5, SNN15, Table 4). This may be brought about by the increased polymer-nanofiller interaction in the polymeric matrix, in which macromolecules are combined with $\mathrm{C}-\mathrm{C}$ crosswise bonds. 


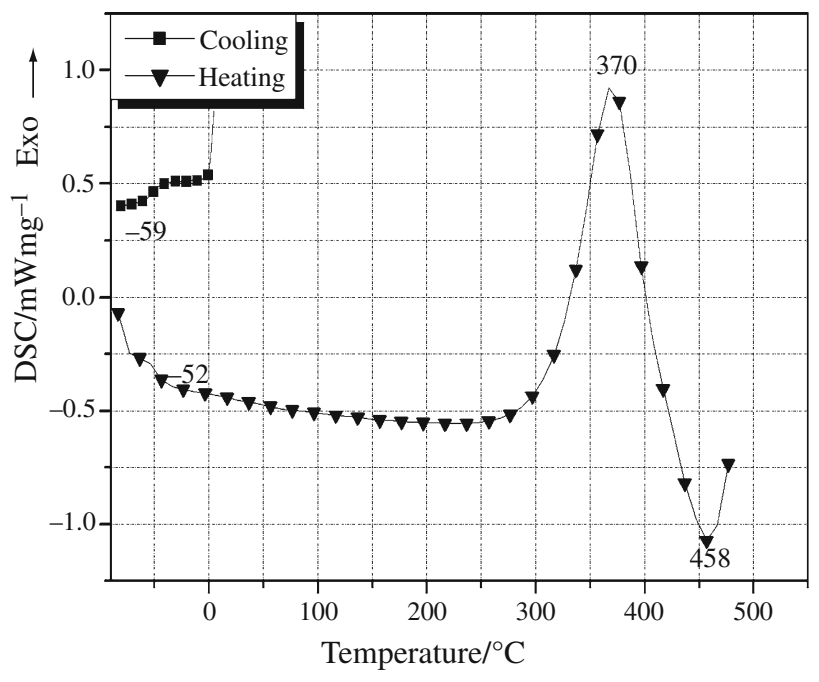

Fig. 9 DSC curves of KER 1500

The results of our study show that the thermal crosslinking processes of SBR contained in the vulcanizates filled with nanofillers begin at a considerably lower temperature regardless of the spatial network structure of the elastomer (Table 4). The yield of these processes, determined with the change in enthalpy $\left(\Delta H_{\mathrm{c}}\right)$, is lower, which is due inter alia to the lower content of the macromolecular component in the nanocomposites under investigation.

The analysis of flammability test results leads to a conclusion that both halloysite nanotubes and modified montmorillonite (Nanofils) decrease the flammability of the cross-linked SBR determined with the value of oxygen index and the combustion time in air $\left(t_{\mathrm{s}}\right)$ (Table 5). The decrease in the flammability of the nanocomposites obtained also results from the considerably increased temperature of their ignition $\left(T_{\mathrm{z}}\right)$. The fire hazard of SBR is also decreased under the influence of the nanofillers tested as indicated by the direction of changes in the maximal rate of heat emission $\left(\mathrm{HRR}_{\max }\right)$ and the total heat emitted (HR) (Table 5).

Both from the literature and our studies it follows that the barrier properties of the halloysite nanotubes used play a great role in reducing the flammability of nanocomposites.

We believe that apart from barrier effects, the lumen of the HNTs plays the leading role in decreasing the flammability of the nanocomposites. During the initial degradation stage of nanocomposites the degradation products of vulcanizates diene rubbers may considerably be entrapped into the lumens of HNTs, resulting higher randomness of lumen ends. The lumen could therefore entrap the degradation products more effectively [27].

The mechanism of the decrease flammability in polymer nanocomposites, especially rubber/MMT is not fully understood yet. It is usually well-accepted that the lower flammability of polymer/clay nanocomposites is not due to retention of a large fraction of fuel, but is mainly due to the formation of char boundary layer, usually observed in exfoliation nanocomposites [28, 29]. Despite this, the exact degradation mechanism is currently not clear, such a behavior is probably associated with the morphological changes in relative portion of exfoliated and intercalated species with the clay loading. As we have mentioned

Table 4 The results of thermal analysis of vulcanizates of SBR rubber in nitrogen atmosphere

\begin{tabular}{|c|c|c|c|c|c|c|c|c|}
\hline \multirow[t]{2}{*}{ Sample } & \multicolumn{2}{|c|}{ Cooling } & \multicolumn{6}{|c|}{ Heating } \\
\hline & $T_{\mathrm{g}} /{ }^{\circ} \mathrm{C}$ & $\Delta T_{\mathrm{g}} /{ }^{\circ} \mathrm{C}$ & $T_{\mathrm{g}} /{ }^{\circ} \mathrm{C}$ & $\Delta T_{\mathrm{g}} /{ }^{\circ} \mathrm{C}$ & $T_{\mathrm{tc}} /{ }^{\circ} \mathrm{C}$ & $\Delta T_{\mathrm{tc}} /{ }^{\circ} \mathrm{C}$ & $\Delta H_{\mathrm{c}} / \mathrm{J} \mathrm{g}^{-1}$ & $T_{\mathrm{d}} /{ }^{\circ} \mathrm{C}$ \\
\hline KER 1500 & -59 & -38 to -68 & -52 & -63 to -23 & 370 & $267-427$ & 593 & 458 \\
\hline SN & -60 & -50 to -78 & -53 & -74 to -34 & 374 & $256-426$ & 594 & 462 \\
\hline SS & -45 & -31 to -61 & -41 & -59 to -19 & 364 & $240-420$ & 571 & 456 \\
\hline SNH5 & -53 & -30 to -70 & -48 & -66 to -26 & 368 & $234-420$ & 453 & 453 \\
\hline SNH8 & -52 & -46 to -57 & -48 & -53 to -44 & 367 & $216-420$ & 473 & 459 \\
\hline SNH15 & -50 & -43 to -57 & -44 & -50 to -39 & 367 & $217-420$ & 396 & 461 \\
\hline SSH5 & -43 & -30 to -60 & -40 & -64 to -24 & 369 & $220-420$ & 493 & 461 \\
\hline SSH8 & -48 & -40 to -58 & -44 & -50 to -38 & 363 & $208-418$ & 421 & 456 \\
\hline SSH15 & -49 & -40 to -60 & -45 & -51 to -39 & 364 & $245-421$ & 387 & 459 \\
\hline SNN2 & -51 & -42 to -64 & -46 & -63 to -23 & 371 & $237-420$ & 504 & 466 \\
\hline SNN5 & -52 & -43 to -66 & -49 & -62 to -22 & 370 & $230-421$ & 513 & 465 \\
\hline SNN15 & -50 & -40 to -60 & -45 & -62 to -32 & 371 & $257-427$ & 435 & 464 \\
\hline SSN2 & -45 & -31 to -56 & -42 & -66 to -25 & 371 & $234-434$ & 470 & 467 \\
\hline SSN5 & -46 & -38 to -56 & -41 & -62 to -22 & 372 & $228-428$ & 439 & 469 \\
\hline SSN15 & -46 & -35 to -55 & -42 & -65 to -24 & 372 & $215-435$ & 486 & 468 \\
\hline
\end{tabular}

$T_{\mathrm{g}}$ glass transition temperature, $\Delta T_{\mathrm{g}}$ temperature range of glass transition, $T_{\mathrm{tc}}$ temperature of thermal cross-linking, $\Delta T_{\mathrm{tc}}$ temperature range of thermal cross-linking, $\Delta H_{\mathrm{c}}$ change of thermal cross-linking enthalpy, $T_{\mathrm{d}}$ temperature of destruction max. rate 


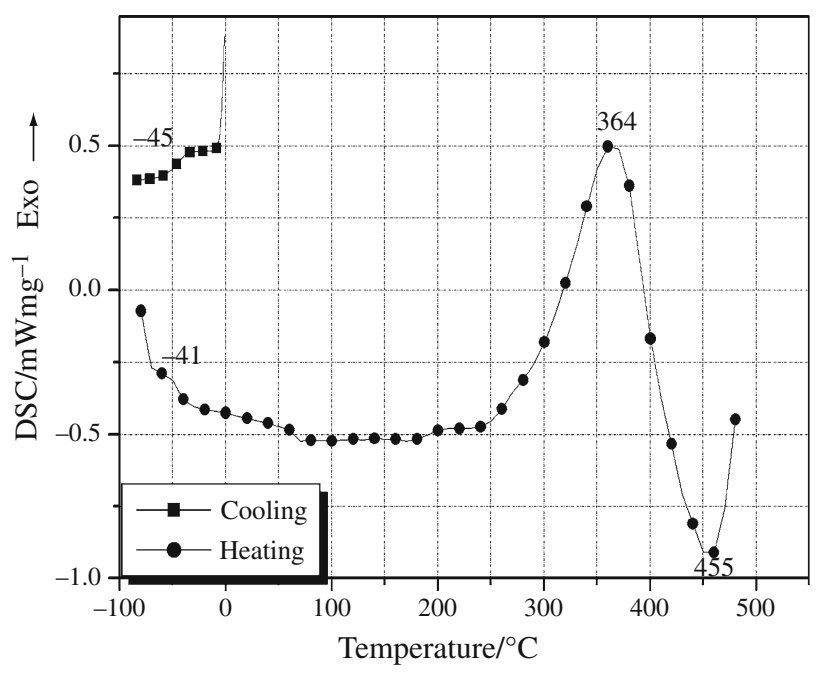

Fig. 10 DSC curves of SS vulcanizate

above, at low clay loading (1-3 wt \%), exfoliation dominates but the amount of exfoliated nanoclay is not enough to enhance the thermal stability through char formation [29]. When increasing the clay concentration (4-8 wt \%), much more exfoliated clay is formed, char forms more easily and effectively and consequently promotes to decrease of flammability of the nanocomposites. At even higher clay loading level (up to $10 \mathrm{wt} \%$ ), the intercalated structure is the dominant population and, even if char formed in high quantity, the morphology of the nanocomposite probably does not allow for maintaining a good thermal stability. In our opinion many aggregates makes in polymer matrix during addition nanoparticles above $10 \mathrm{wt} \%$. In poor dispersion conditions, the distance between the aggregates "isolated island of nanofillers" were exposed to undiminished external heat flux, polymer chains without protection were burnt out quickly.

Both from the literature and our studies it follows that the layered silicates appeared to enhance the performance of the char layer, which acted as an insulator and mass transport barrier and therefore reduced the mass loss rate and improved flammability and thermal stability (Fig. 11). Yano et al. [30] experimental and theoretical work reported that polymer/clay nanocomposites, the permeability coefficient of volatile gases, such as water vapor and $\mathrm{He}$, was remarkably decreased. The observed "labyrinth effect" is also thought to play important role in thermal stability improving of polymer/MMT nanocomposites since composite material having poor dispersity of MMT usually exhibit no thermal improvement or the effect is poor in comparison to well exfoliated or intercalated nanocomposites.

The diffusion of oxygen into nanocomposite is also considerably impeded as indicated by the value of percentage oxygen consumption (Table 5; Fig. 12), which reduces the yield of radical degradation reactions and polymer depolymerization during its combustion, consequently increasing its resistance to the action of flame [31].

\section{Summary}

The nanofillers used do not explicitly influence the thermal stability of the nanocomposites tested but they decrease the thermal decomposition rate of these materials under thermo-oxidative conditions. Under the influence of the halloysite intercalated with a base the contribution of the cyclization and carbonization reaction is increased in the

Table 5 Flammability test results of butadiene-styrene rubber nanocomposites

\begin{tabular}{|c|c|c|c|c|c|c|c|c|}
\hline Sample & OI & $\begin{array}{l}\text { Combustion } \\
\text { time in air/s }\end{array}$ & $T_{\mathrm{z}} /{ }^{\circ} \mathrm{C}$ & $H R \mathrm{R}_{\max } / \mathrm{W} \mathrm{g}^{-1}$ & $\begin{array}{l}\text { Total } \\
\mathrm{HR} / \mathrm{kJ} \mathrm{g}^{-1}\end{array}$ & HR Capacity/J g ${ }^{-1} \mathrm{~K}^{-1}$ & $\begin{array}{l}\text { Residue after } \\
\text { burning/\% }\end{array}$ & $\begin{array}{l}\text { Oxygen } \\
\text { consumption/\% }\end{array}$ \\
\hline $\mathrm{SN}$ & 0.210 & 194 & 350 & 450 & 34.5 & 501 & 21.11 & 40.11 \\
\hline SS & 0.220 & 273 & 355 & 399,8 & 34.3 & 397 & 14.31 & 44.91 \\
\hline SNH5 & 0.225 & 247 & 365 & 431 & 32.8 & 422 & 11.26 & 41.71 \\
\hline SNH8 & 0.233 & 302 & 374 & 428 & 33.6 & 417 & 7.88 & 28.55 \\
\hline SNH15 & 0.239 & 336 & 369 & 403 & 30.0 & 394 & 14.23 & 33.12 \\
\hline SSH5 & 0.234 & 405 & 358 & 373 & 33.4 & 366 & 4.65 & 28.27 \\
\hline SSH8 & 0.241 & 415 & 365 & 384 & 31.2 & 387 & 7.36 & 26.55 \\
\hline SSH15 & 0.252 & 432 & 365 & 356 & 30.2 & 347 & 15.54 & 30.03 \\
\hline SNN2 & 0.227 & 315 & 357 & 321 & 34.4 & 396 & 8.28 & 49.83 \\
\hline SNN5 & 0.232 & 310 & 363 & 334 & 33.5 & 333 & 11.1 & 39.25 \\
\hline SNN15 & 0.230 & 281 & 372 & 271 & 33.5 & 340 & 13 & 40.06 \\
\hline SSN2 & 0.230 & 305 & 383 & 281 & 32.8 & 331 & 4.02 & 29.72 \\
\hline SSN5 & 0.240 & 310 & 379 & 238 & 32.8 & 311 & 10.36 & 46.50 \\
\hline SSN15 & 0.235 & 290 & 377 & 242 & 33.3 & 316 & 10.36 & 53.65 \\
\hline
\end{tabular}

$O I$ oxygen index, $T_{\mathrm{z}}$ temperature of ignition, $H R R_{\max }$ maximum heat release rate, Total HR total heat release 


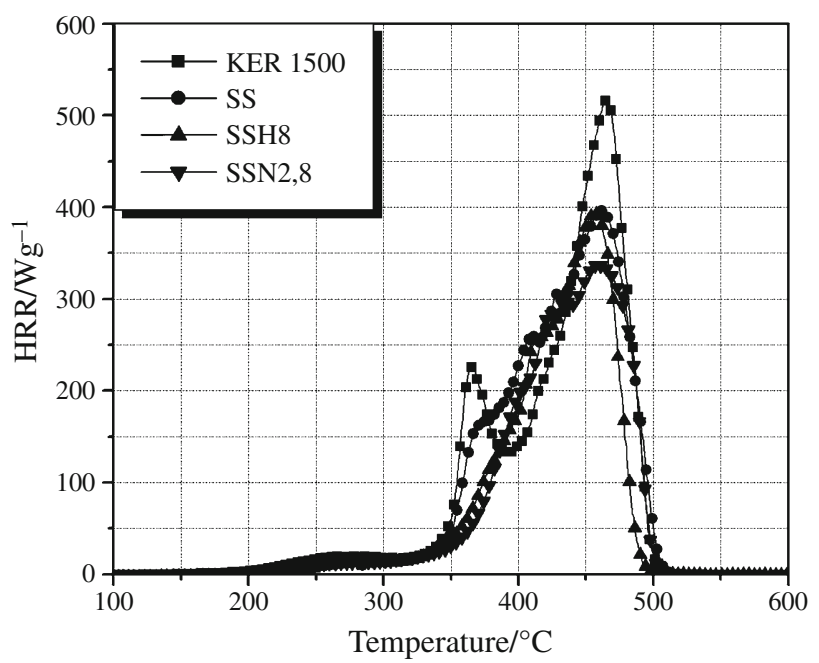

Fig. $11 \mathrm{HRR}_{\text {max }}$ during combustion investigated nanocomposites

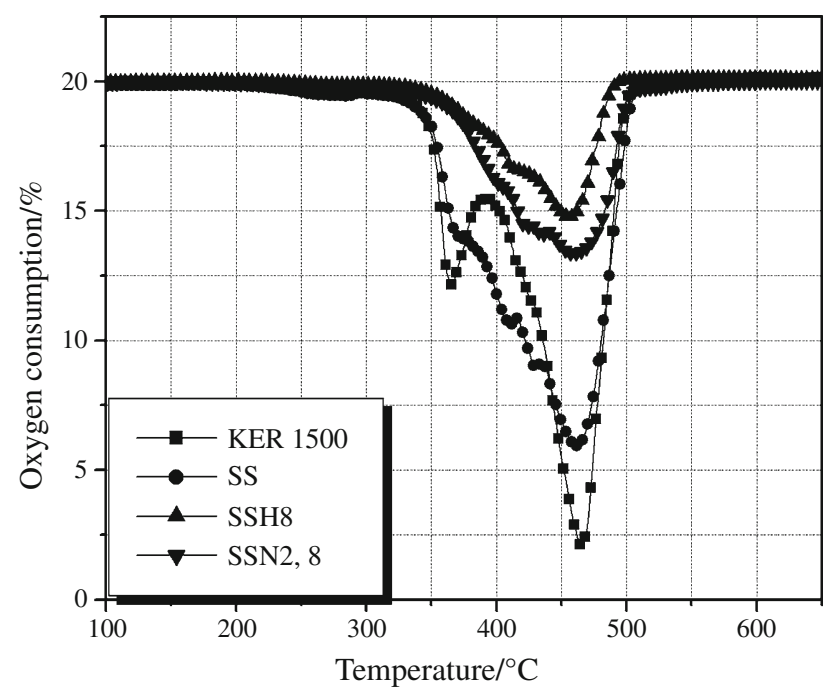

Fig. 12 Oxygen consumption during combustion investigated nanocomposites

processes of elastomer destruction. Both halloysite nanotubes and modified montmorillonite (Nanofils) decrease the flammability of the cross-linked styrene-butadiene rubber, which is also accompanied by a reduction in fire hazard resulting from the use of the nanocomposites tested.

Open Access This article is distributed under the terms of the Creative Commons Attribution License which permits any use, distribution, and reproduction in any medium, provided the original author(s) and the source are credited.

\section{References}

1. Samarzija-Jovanović S, Jovano V, Marković G, Konstantinović S, Marianović-Cinović M. Nanocomposites based on silica- reinforced ethylene-propylene-diene monomer/acrylonitrilebutadiene rubber blends. Composites Part B. 2011;42:1244-50.

2. Rybiński P, Janowska G, Ślusarski L. Influence of cryogenic modification of silica on thermal properties and flammability of cross-linked nitrile rubber. J Therm Anal Calorim. 2010; 101:665-70.

3. Chrissafis K, Bikiaris D. Can nanoparticles really enhance thermal stability of polymers? Part I: an overview on thermal decomposition of addition polymers. Termochim Acta. 2011; 523(1-2):1-24. doi:10.1016/j.tca.2011.06.010.

4. Paul DR, Robeson LM. Polymer nanotechnology: nanocomposites. Polymer. 2008;49:3187-204.

5. Leszczyńska A, Njuguna J, Pielichowski K, Banerjee JR. Polymer/montmorillonite nanocomposites with improved thermal properties. Part I. Factors influencing thermal stability and mechanisms of thermal stability improvement. Termochimica Acta. 2007;453:75-96.

6. Maksimov RD, Gaidukovs S, Kalnins M, Zicans J, Plume E. A nanocoposite based on a styrene-acrylate copolymer and native montmorillonite clay. Mech Compos Mater. 2006;42:45-54.

7. Sorina-Alexandra G, Horina J, Ancuta B. New organophilic agents of montmorillonite used as reinforcing agent in epoxy nanocompostes. Polym Test. 2008;27:100-13.

8. Olewnik E, Garman K, Czerwiński W. Thermal properties of new composites based on nanoclay, polyethylene and polypropylene. J Therm Anal Calorim. 2010;101:323-9.

9. Yong-Lai Lu, Li Zhao, Zhong-Zhen Yu, Ming Tian, Li-Qun Zhang, Yiu-Wing Mai. Microstructure and properties of highly filled rubber/clay nanocomposities prepared by melt blending. Compos Sci Technol. 2007;67:2903-13.

10. Wu Y-P, Wang Y-Q, Zhang H-F, Wang Y-Z, Yu D-S, Zhang L-Q, Yang Y. Rubber-pristine clay nanocomposites prepared by co-coagulating rubber latex and clay aqueous suspension. Compos Sci Technol. 2005;65:1195-202.

11. Gilman JW. Flammability and thermal stability studies of polymer layered-silicate (clay) nanocomposites. Appl Clay Sci. 1999; 15:31-49.

12. Ma HY, Song PA, Fang ZP. Flame retarded polymer nanocomposites: development, trend and future perspective. Sci China Chem. 2011;54(2):302-13.

13. Kashiwagi T, Grulke E, Hilding J, Harris R, Award W, Douglas J. Thermal degradation and flammability properties of polypropylene/carbon nanotubes composites. Macromol Rapid Commun. 2002;23(13):761-5.

14. Handge UA, Hedicke-Hochstotter K, Altstadt V. Composites of polyamide 6 and silicate nanotubes of mineral halloysite: influence of molecular weight on thermal and rheological properties. Polymer. 2010;51:2690-9.

15. Guo B, Chen F, Lei Y, Liu X, Wan J, Jia D. Styrene-butadiene rubber/halloysite nanotubes nanocomposites modified by sorbic acid. Appl Surf Sci. 2009;255:7329-36.

16. Horvath E, Kristof J, Kurdi R, Mako E, Khunova V. Study of urea intercalation into halloysite by thermoanalytical and spectroscopic techniques. J Therm Anal Calorim. 2011;105:53-9.

17. Pasbakhsh P, Ismail H, Ahmad Fauzi MV, Abu Bakar A. EPDM/ modified halloysite nanocomposites. Appl Clay Sci. 2010;48: 405-13.

18. Rooj S, Das A, Thakur V, Mahaling RN, Bhowmick AK, Heinrich G. Preparation and properties of natural nanocomposites based on natural rubber and naturally occurring halloysite nanotubes. Mater Des. 2010;31:2151-6.

19. Rybiński P, Janowska G, Jóźwiak M, Pająk A. Thermal properties and flammability of nanocomposites based on diene rubbers and naturally occurring and activated halloysite nanotubes. J Therm Anal Calorim. 2012;107:1243-9. doi:10.1007/s.10973011-1787-z. 
20. Janowska G, Kucharska-Jastrząbek A, Rybiński P. Thermal stability, flammability and fire hazard of butadiene-acrylonitrile rubber nanocomposites. J Therm Anal Calorim. 2011;103: 1039-46.

21. Rybiński P, Janowska G, Kucharska-Jastrząbek A, Pająk A, Wójcik I, Wesołek D, Bujnowicz K. Flammability of vulcanizates of diene rubbers. J Therm Anal Calorim. 2012;107:1219-24. doi:10.1007/s.10973-011-1728-x.

22. Gong F, Feng M, Zhao C, Zheng S, Yang M. Thermal properties of poly(vinyl chloride)/montmorillonite nanocomposites. Polym Degrad Stab. 2004;84:289-94.

23. Rybiński P, Janowska G. Influence of network structures of nitrile rubbers on their thermal properties. Polimery. 2009;54:35-42.

24. Rybiński P, Janowska G, Kucharska- Jastrząbek A. Thermal properties and flammability of nanocomposites based on butadiene-acrylonitrile rubber. Modern polymeric materials for environmental applications, vol 4. 4th International seminar including COST MP0701 workshop Kraków, Kraków; 2011. p .95-106.

25. Pagacz J, Pielichowski K. Preparation and evaluation of PVC/ MMT nanocomposites properties produced by solution casting method. Chemistry Technical Transactions, vol 4. Technical University of Kraków, Kraków; 2009. p. 95-110.

26. Ma $\mathrm{H}$, Tong $\mathrm{L}, \mathrm{Xu} \mathrm{Z}$, Fang Z. Intumescent flame retardantmontmorillonite synergism in ABS nanocomposites. Appl Clay Sci. 2008;42:238-45.

27. Bikiaris D. Microstructure and properties of polypropylene/carbon nanotubes nanocomposites. Materials. 2010;3:2884-946.

28. Alexandre M, Dubois P. Polymer-layered silicate nanocomposites: preparation, properties and uses of a new class of materials. Mater Sci Eng. 2000;28:1-63.

29. Yano K, Usuki A, Kurauchi T, Kamigaito O. Synthesis and properties of polyimide-clay hybrid. J Polym Sci, Part A. 1993; 31:2493-8.

30. Du M, Guo B, Jia D. Thermal stability and flame retardant effects of halloysite nanotubes on poly(propylene). Eur Polymer J. 2006; 42:1362-9.

31. Pavlidou S, Papaspyrides CD. A review on polymer-layered silicate nanocomposites. Prog Polym Sci. 2008;33:1119-98. 